\title{
APLICAÇÃO DA LEI 11.340/2006 EM CRIMES PERPETRADOS CONTRA PROFISSIONAIS DO SEXO
}

Gilberto Batista Santos ${ }^{1}$

\section{RESUMO}

O principal objetivo desse trabalho é expor a possibilidade do uso da Lei Maria da Penha como meio punitivo aos crimes cometidos contra profissionais do sexo, de acordo com as circunstâncias e as relações íntimas de afeto existentes entre garotas de programa e seus clientes. Para tanto, aplica-se à pesquisa o método dedutivo e método de Abordagem Baseada em Direitos (Right-Based Aprooach - RBA), sendo a mesma vinculada ao Grupo de Pesquisa Gestão, Educação e Direitos Humanos (GEDH), na realização de projetos em Direitos Humanos na Universidade do Estado da Bahia (UNEB).

Palavras-Chaves: Abordagem Baseada em Direitos; Lei Maria da Penha; Mulher; Profissional do sexo; Violência de Gênero.

\section{APPLICATION OF LAW 11.340 /2006 IN CRIMES PERPETRATED AGAINST SEX PROFESSIONALS}

\begin{abstract}
The main objective of this work is to expose the possibility of using the Maria da Penha Law as a punitive means for crimes committed against sex workers, according to the circumstances and the intimate relationships of affection existing between call girls and their clients. To this end, the deductive method and the Right-Based Approach (RBA) method are applied to research, which is linked to the Management, Education and Human Rights Research Group (GEDH), in carrying out projects in Human Rights at the State University of Bahia (UNEB).
\end{abstract}

KeyWords: Right-Based Aprooach ;Gênder Violence; Law Maria da Penha; Sex Professional; Woman.

\section{INTRODUÇAO}

Sucede que, o tema a ser abordado é voltado para o estudo da violência baseada no gênero, sofrida por mulheres e de como isso é um dos grandes problemas ocasionados pela cultura de modelo familiar patriarcal que sempre colocou a mulher em situação de

\footnotetext{
${ }^{1}$ Professor Universitário; Advogado do Centro de Referência em Desenvolvimento e Humanidades CRDH/UNEB; Pesquisador do Observatório da Educação em Direitos Humanos (OBEDHUC); Bacharel em Direito pela Universidade do Estado da Bahia - UNEB; Mestre em Tecnologia Aplicada a Educação pela Universidade do Estado da Bahia - UNEB; Graduando em História pela Universidade do Estado da BahiaUNEB.
} 
dependência e subordinação ao homem.

Diante de uma Lei tão vasta e afamada, que determina que violência doméstica e intrafamiliar pode ocorrer também em relacionamentos afetivos que independam de coabitação física, fica se o questionamento: Pode-se dá a aplicação da referida Lei em situações de violência doméstica cometidas contra Profissionais do Sexo?

No desenvolver do estudo, entende-se que dependendo da circunstância em que a violência foi cometida, há sim tal possibilidade. Por mais que haja divergência doutrinária a esse respeito, mas caso o crime seja cometido sob um contexto que caracterize a violência doméstica, não há por que se negar a aplicabilidade da norma para fazer justiça frente ao delito. Para tanto, aplica-se à pesquisa o método dedutivo e método de Abordagem Baseada em Direitos (Right-Based Aprooach - RBA), sendo a mesma vinculada ao Grupo de Pesquisa Gestão, Educação e Direitos Humanos (GEDH), na realização de projetos em Direitos Humanos na Universidade do Estado da Bahia (UNEB).

\section{DA PROFISSÃO DE “GAROTA DE PROGRAMA”}

A garota de programa, também conhecida pelas denominações de prostituta, profissional do sexo, meretriz, messalina, michê, mulher da vida, trabalhadora do sexo nomenclaturas dada pela Classificação brasileira de Profissões (CBO), do Ministério do Trabalho do Brasil - é a protagonista dessa relação constituída pela troca de favores sexuais, caracterizando a prostituição.

Considerada pelo senso comum, sem nenhuma fonte de dados, como "a mais antiga profissão do mundo", a prática da prostituição nem sempre se dá pela troca de sexo por dinheiro, de acordo com o psicanalista e estudioso do tema, Paulo roberto Ceccarelli, o termo na verdade, refere-se a troca de benefícios por sexo, podendo ser qualquer coisa ou ato que venha a beneficiar quem está a vender seu corpo, Ceccarelli assegura que "pode-se cambiar relações sexuais por favores profissionais, informações, bens materiais e muitas outras coisas." (CECCARELLI, 2008).

A visão que é dada a prostituta pela sociedade, varia de acordo com a época e a cultura; nem sempre foi acompanhada do estigma que as tradições ocidentais lhe atribuem. Sendo essa atribuição negativa, devido a visão que se tem da sexualidade, tratada até hoje como um 'tabu', algo bem contrário da antiguidade, em que não havia a noção de pecado ligado ao sexo. 
A prostituição nem sempre foi vista como algo imoral e despudorada, civilizações antigas tratavam do assunto como algo natural que fizesse parte das relações sociais. Ceccarelli ressalta que em algumas civilizações a prostituição tratava-se de um ritual de passagem praticado pelas meninas ao atingirem a puberdade; em outras, os homens iniciavam sexualmente as jovens em troca de presentes. (CECCARELLI, 2008).

Ainda segundo estudos do psicanalista, algumas formas de prostituição já foram vinculadas a divindades, como nas primeiras civilizações da Mesopotâmia e do Egito, onde sacerdotisas prostitutas, consideradas sagradas, recebiam presentes em troca de favores sexuais. Na Grécia antiga, havia as hierodule, mulheres sagradas que ofereciam serviços sexuais em ocasiões especiais, mas não correspondiam exatamente ao que entendemos por prostitutas. Eram vistas como a encarnação de Afrodite e respeitadas pela população e pelos governantes por evocarem o amor, o êxtase e a fertilidade.” (CECCARELLI, 2008).

Já na antiga civilização grega, a prostituição fazia parte do cotidiano, era um meio de obtenção de renda igual a qualquer outro e uma prática controlada pelo estado, que arrecadavam impostos pagos pelas prostitutas. Paulo Ceccarelli descreve a vida social de uma prostituta na Grécia antiga de tal forma:

Entre as várias categorias, havia as hetairas, de grande relevância social, conhecidas pela inteligência, esperteza na administração dos bens e competência nas articulações políticas. Frequentavam livremente o universo masculino e participavam das atividades reservadas aos homens. Trabalhavam nos bordéis do Estado, sem sofrerem qualquer represália. As hetairas eram formadas em escolas nas quais as aspirantes aprendiam a arte do amor, a literatura, a filosofia e a retórica, vindo a ser as mulheres mais instruídas da Grécia. (CECCARRELLI, 2008).

Deste modo observa-se que se tratava de mulheres com uma base educacional instruídas em diversos campos sociais da época, convivendo de forma comedida com o corpo social que não apresentava nenhum problema em coexistir com essas mulheres, vez que, a sociedade da época era desprendida de preconceitos quanto a sexualização e a forma como era praticada.

$\mathrm{Na}$ cultura judaica, por sua vez, a prostituição era severamente punida; porém havia certa tolerância, como mostra na história de Jesus, o ato dele não permitir que uma mulher acusada de prostituição fosse apedrejada, e tal ato foi acatado pelos demais que desistiram de cometer a agressão. 
Na Idade Média Europeia, no século XVI, houve a Reforma religiosa, o puritanismo passou a controlar os costumes e ditar a moral, com isso então, a prostituição caiu na clandestinidade, contudo, não foi eliminada.

A igreja Católica condenava a prática, porém, defendia a sua utilidade, como Manuela Tavares preleciona:

\begin{abstract}
A própria Igreja em plena Idade Média oscila quanto ao posicionamento face à prostituição. Por um lado, era condenada, mas por outro lado defendia-se a sua utilidade para evitar que as "pressões sexuais" masculinas fossem dirigidas às "mulheres sérias". Esta concepção de salvaguarda das mulheres sérias serviu de base à defesa da prostituição como uma instituição social de serviço público, que deveria ser tolerada e regulada. (TAVARES, 2013).
\end{abstract}

Observa-se uma diferenciação, feita pelo clero, entre as mulheres, classificando-as como objeto de prazer e mulheres "sérias", devendo estarem em polos opostos no corpo social. À mulher "séria" era negado o prazer sexual pois tala exaltação, para a sociedade da época, poderia fazer dela uma prostituta.

De acordo com Manuela Tavares, durante o século XIX ocorreu o sistema de regulação estatal em praticamente todos os países europeus, "registro de prostitutas, exames médicos obrigatórios pagos pelas próprias, internamento compulsivo em instituições quando estivessem infectadas com doença venérea. Os homens, envolvidos na qualidade de clientes, ficavam de fora, já que a raiz de todo o mal estaria na mulher" (TAVARES, 2013).

A partir da Revolução Industrial a situação da mulher ganhou um novo rumo, as mulheres passaram a exercer trabalhos de mão-de-obra nas indústrias, assim como os homens, e por questões de força física enfrentaram condições desiguais no trabalho em relação ao homem. Prostituir-se em troca de favores, de melhores condições de vida, ou do sustento revelou-se uma opção. (CECCARELLI, 2008).

Os primeiros movimentos internacionais contra a exploração sexual de mulheres, começaram no final do século XIX na Europa, foram impulsionados por feministas que consideravam a prostituição um tipo de escravidão sexual. Inicia-se então nesse período, um movimento contra o regulamentarismo da prostituição. (TAVARES, 20230.

Segundo pesquisa realizada pelo Ministério da Saúde do Brasil, boa parte das garotas que se prostituem são jovens com menos de quarenta anos. Estima-se que a maioria dessas pessoas se prostitui para sobreviver e guarda a esperança de encontrar um grande amor e mudar de vida. (MS- BR, 2008). 
A garota de programa é vista pelos homens como sexo sem entraves, sexo totalmente da forma que eles, na condição de cliente, desejarem. A ponto de mesmo vivendo uma situação afetivo-sexual satisfatória com uma parceira fixa, ainda procuram prostitutas.

Ceccarelli apresenta que, graças à liberação sexual, jovens que poderiam iniciar a vida sexual com colegas ou namoradas, preferem buscar profissionais do sexo para a iniciação, buscando satisfazer seus desejos exaltados. (CECCARELLI, 2008).

A prostituição é relacionada a comportamentos e práticas sexuais marginais. Relações totalmente informais - na maioria das vezes, mas nem sempre -, que tem como único elemento o sexo e são feitas de forma sigilosa, por interesse principal do cliente, vez que, para o homem é degradante ter a sua imagem associada à uma mulher que é rechaçada e tem sua prática "profissional" marginalizada pela sociedade, servindo esta apenas para um momento de prazer.

Mas há casos em que a relação cliente e profissional do sexo vai além do que meros momentos de regozijo sexual sem maiores vínculos. É sabido de casos mais profundos com laços sentimentais entre esses cúmplices e até mesmo de desejos masculinos de ter um relacionamento informal, porém sentimental, com garotas de programa. Porém, isto será pauta para o próximo item deste capítulo.

Não se pode negar que no Brasil a miséria seja um dos fatores preponderantes que levam as mulheres à prostituição. Entretanto, não é o único, não se pode relacionar o ingresso a prostituição somente a fatores negativos, de modo que, essa fosse a única saída para a resolução dos problemas da mulher que ingressa nesse ramo, há de se considerar também a opção de livre escolha da mulher de conduzir sua vida sexual como melhor lhe convier fazendo da prostituição uma escolha como qualquer outra.

Como exprime Ceccarelli, a profissional do sexo não existe sem o cliente. Entre eles há um movimento mútuo e complementar de oferta e demanda, existe, de ambos os lados, desejos em busca de satisfação e promessa de satisfazê-los, por razões como esta, que a prostituição sempre existiu e continuará existindo, mesmo nos lugares em que sua prática seja oficialmente proibida. Todos os elementos presentes na construção do universo erótico da prostituição (local, formas de sedução, promessas, confidências, preço, adereços, vestimentas, fetiches, etc.) se misturam de forma que é impossível saber quem está 
realizando a fantasia de quem, embora, objetivamente, os papéis estejam bem definidos. (CECCARELLI, 2008).

A prostituição pode ser entendida também como sinônimo de submissão e dominação masculina, já que a mulher é obrigada a se submeter a situações violentas e perigosas perante o homem, seja na forma de aliciador ou de cliente.

Ceccarelli afirma:

\begin{abstract}
A prostituição constitui mais uma manifestação da cultura machista, pois, em certa medida, a sexualidade feminina continua sendo gerenciada pelos homens. Além disso, a sociedade que cria fiscalizações, sanções e punições às atividades de prostituição em nome da moralidade e dos bons costumes é a mesma que cria subterfúgios para manter esses serviços ativos e disponíveis quando a ocasião, e/ou a necessidade, se apresentar. (CECCARELLI, 2008).
\end{abstract}

De forma muito sensata, o autor faz uma crítica da forma hipócrita que a questão da prostituição é tratada, e de forma clara, é perceptível como essa prática está associada a dominação masculina, que objetifica, discrimina, violenta, tira vantagens desiguais das prostitutas, mas em contra partida, à medida que censuram também apreciam sua utilidade para o seu bel-prazer.

Refletir sobre a prostituição é aprofundar o debate sobre as relações de dominância entre homens e mulheres, levando em conta as questões ligadas à posição subjetiva da mulher na sociedade, em particular a da prostituta, e a hegemonia do discurso masculino dominante que pode levar a questão da violência de gênero e a necessidade da intervenção do poder público como medida de defesa a essas mulheres terem uma vida como desejarem exercendo seus direitos de não sofrerem violência sob nenhum aspecto e de nenhum tipo, pois não há nada que justifique isso.

\title{
VIOLÊNCIA BASEADA NO GÊNERO CONTRA PROFISSIONAIS DO SEXO
}

De acordo com o Relatório Mundial sobre Violência e Saúde da OMS publicado em 2002, e redigido por Etienne G. Krug: a violência é um fenômeno que está presente na história da humanidade. É uma questão social que afeta a saúde das pessoas, sendo uma das principais causas de morte no mundo, na faixa etária de 15 a 44 anos. (KRUG, 2002).

A violência atinge a todos que se encontrar em situação de vulnerabilidade, não exclui classes sociais, raças, sexo, etnias, etc. O Ministério da Saúde no Brasil afirma que é considerada como fenômeno crescente em toda sociedade, apresentando-se de várias formas e que representa uma das principais causas de morte no mundo. (MS-BR, 2002). 
Ainda de acordo com o Ministério da Saúde, para a sociedade, a atividade exercida por garotas de programa é moralmente reprovável, além de serem expostas a violência ainda maior, advém o fato de que o ambiente em que elas trabalham as deixem mais vulneráveis, pois, na rua, estão submetidas às agressões arbitrárias. (MS-BR, 2002).

Torna salutar informar, que por motivos de delimitação, tratar-se-á aqui somente da violência cometida contra mulheres profissionais do sexo adultas, sendo estas cissexuais, o que não significa que homens, transexuais ou crianças e adolescentes que sofram violência por exercerem o mesmo tipo de atividade não mereçam a devida importância.

Nessa prática, as mulheres oferecem regozijo sexual em troca de remuneração, criando, por vezes, passam a ter laços de intimidade com o parceiro sexual, pois, pode vir a realizar a atividade repetidas vezes com a mesma pessoa. Segundo Nicolau, Aquino e Pinheiro, a repetição de encontros é uma das razões para se obter o vínculo.

Os autores prelecionam que assim como pode surgir um vínculo afetivo com o parceiro, pode também surgir os fatores de risco, colocando em perigo à sua integridade física, sexual, psíquica, a sua liberdade e até mesmo sua vida, além de sofrem ofensas moral. (NICOLAU, AQUINO e PINHEIRO, 2008).

Izabel Cristina Moreira e Claudete Monteiro apresentam que:

\footnotetext{
$\mathrm{Na}$ esteira desse caminho de riscos, as mulheres prostitutas continuam sendo alvo da violência pelos clientes, por esses entenderem que o pagamento lhes confere poder para o abuso físico, sexual e psicológico, como também pela interpretação da imagem da prostituta, a qual ainda sofre influências do passado (MOREIRA e MONTEIRO, 2016).
}

Dessa forma, compreende-se que a violência contra profissionais do sexo está intrinsecamente ligada a violência de gênero, onde o agressor aufere o direito de agredir à vítima ao fato de estar pagando pelo "serviço", considerando assim que estas não me reçam qualquer tipo de respeito, pensamento este que é compartilhado por parte da sociedade.

Torna-se necessário dar visibilidade a essa violência, dar voz a esse grupo de risco, para se compreender como é o vivido da violência, o que sentem essas mulheres e como as políticas públicas podem aproximar-se mais para desenvolver trabalhos de promoção a prevenção da violência, no cotidiano dessa atividade. (MOREIRA e MONTEIRO, 2016).

Para se compreender melhor o que de fato são profissionais do sexo e a atividade desenvolvida por elas, destaca-se alguns conceitos que são importantes nessa construção. A definição de profissão é dada por L. Walther como, uma atividade econômica destinada a 
assegurar a manutenção da vida. Caracteriza-se como um conjunto de habilidades, adquiridas mediante certa aprendizagem, seja de que gênero for. (WALTHER, 1962).

Quanto a atividade sexual, o especialista em ginecologia, Sérgio Passos Ramos, define como "qualquer aproximação íntima que envolva os órgãos sexuais das pessoas, ou seja: entre pênis, vulva (parte externa do órgão sexual feminino), boca e ânus. Dessa forma, ao contrário do que muitas pessoas pensam, diversas práticas que não necessariamente envolvem a penetração vaginal são consideradas relação sexual. Exemplos: pênis-boca, pênis-vulva, pênis-ânus, vulva-vulva, entre outras possibilidades.” (RAMOS, 2017).

Em sentido estrito e comum, Nucci faz algumas considerações à respeito do conceito de prostituição, de acordo com ele, "a prostituição é o comércio sexual do próprio corpo, geralmente desenvolvido com habitualidade, objetivando o sustento". Preleciona ainda que, "o verbo prostituir possui significados variados, abrangendo a visão de comercialização do sexo, além de desmoralizar, corromper, degradar, desonrar, auferindo intenso conteúdo moral - na realidade, imoral” (NUCCI, 2015).

Nucci expõe ainda que, "prostituição, de um ponto de vista etimológico, significa colocar adiante (de prostituere), ou colocar à venda. Assim, pode-se facilmente individuar o fenômeno sob dois aspectos diferentes, mesmo que intimamente conexos entre eles. De um primeiro ângulo, a prostituição é considerada como qualquer tipo de prestação sexual, que, quando executada, corresponde a um preço. Sob outro prisma, corresponde a uma submissão, à qual está sujeito aquele que se dedica à prostituição, altamente lesivo à dignidade humana." (NUCCI, 2015).

Colocados em evidência a descrição dos termos acima, conclui-se que a prostituição é a junção da profissão com a atividade sexual, onde garotas de programa - profissionais do sexo - comercializam seus corpos oferecendo prazer sexual aos homes em troca de dinheiro, objetivando seu sustento.

Porém, frisando o exposto por Nucci, a prostituição pode ser entendida também como algo imoral, lesivo a dignidade humana, que cause desonra e desmoralização. Partindo desse pressuposto, por esta razão que essa "profissão" sofre ainda tamanha discriminação e preconceito pela sociedade, já que está intrinsecamente ligada a desonra moral. 
Juntamente com essa segregação social sofrida por prostitutas, vem-se a violência. $\mathrm{O}$ que tem que se compreender é que por motivo algum se justifica agressões de cunho físico, sexual e qualquer outro. Profissionais do sexo, sem distinção de outras mulheres, devem e precisam ser amparadas pelo poder público.

A Lei Maria da Penha, que possui o cunho de proteger vítimas de violência familiar e doméstica, também deve incidir em casos de agressões às garotas de programa que tenha havido esse fator como ponto de partida para a agressão. Diferentemente do que se imagina, pode haver sim violência de caráter doméstica cometida em prostitutas, à esse respeito já se tem decisão judicial, que será trazida posteriormente.

\section{DA APLICAÇÃO DA LEI MARIA DA PENHA COMO MEIO PUNITIVO Á VIOLÊNCIA DOMÉSTICA SOFRIDA POR PROFISSIONAIS DO SEXO}

Os mecanismos jurídicos existem para regulamentar uma sociedade, a legislação tem como um de seus deveres, punir os infratores e dar a devida assistência às vítimas e isto deve aplicar-se a todos de forma geral, sem distinção. Deste modo, uma lei com tamanha visibilidade e importância no Brasil, não deve se omitir diante de agressões que representam seu tipo penal, não devendo se restringir apenas a agressões sofridas no âmbito familiar ou de coabitação física.

De acordo com o artigo $5^{\circ}$ da Lei 11.340/2006, configura violência doméstica e familiar contra a mulher, qualquer ação ou omissão baseada no gênero que lhe cause morte, lesão, sofrimento físico, sexual ou psicológico e dano moral ou patrimonial; ainda sob ótica desse mesmo artigo no inciso III, a relação do agressor com a vítima independe de coabitação, basta existir qualquer relação íntima de afeto. (BRASIL, 2006).

Graças a sensatez do legislador ao elaborar a lei, descreveu como crime doméstico incluindo qualquer relação íntima de afeto, na qual o agressor conviva ou tenha convivido com a ofendida, independentemente de coabitação (inciso III). E por relação íntima de afeto ou afetividade, entende-se que é o conjunto dos fenômenos afetivos (emoções, sentimentos) constituídos em uma relação. (SILVA, 2013).

Isto muda o conceito antiquado de que violência doméstica seria apenas aquela sofrida dentro de casa pelo companheiro. Desta forma, a aplicabilidade da Lei Maria da Penha tornase maior, podendo atingir crimes de agressões a profissionais do sexo, por exemplo. A esse respeito, já existe decisão judicial favorável a vítima. 
No ano em que completou dez anos, a Lei Maria da Penha passa a ser capaz de proteger ainda mais mulheres: numa decisão inédita, a Segunda Câmara Criminal do Tribunal de Justiça do Rio aplicou a legislação - voltada a punir a violência doméstica - no caso da agressão de uma prostituta carioca de 37 anos, espancada por um cliente. Foi expedido um mandado de prisão contra o agressor, um empresário divorciado de 55 anos, morador da Tijuca, como prevê a Lei Maria da Penha, a pena, por lesão corporal gravíssima, foi acrescida em um terço e será de dois anos e oito meses.

O caso, começou a tramitar em 2013, ano em que uma garota de programa, na época com 33 anos, moradora da Barra da Tijuca, sofreu lesões corporais graves - um soco que recebeu na boca fez com que perdesse dentes e passasse a ter comprometimento permanente na mastigação. $\mathrm{O}$ ataque de fúria partiu de um cliente, com quem ela se relacionava há seis anos. A defesa do réu sempre bateu na tecla de que a vítima era garota de programa e, portanto, não havia relação de afeto que justificasse o julgamento numa Vara da Violência Doméstica e Familiar, para onde o processo fora encaminhado.

O empresário acabou condenado a dois anos e oito meses em regime aberto. A defesa não gostou e apelou. O recurso então chegou às mãos dos três desembargadores da Primeira Câmara Criminal do TJ do Rio, que, por dois votos, mantiveram a condenação. Como a decisão não foi unânime, o réu teve direito a embargos infringentes, que foram julgados pelos cinco desembargadores da Segunda Câmara Criminal.

De um lado, a defesa, não negava as lesões corporais, mas alegava que elas teriam sido uma atitude de legítima defesa. Porém, insistia na tese de que o réu apenas gostava de contratar serviços de garotas de programa e tratava-se, portanto, de uma relação sem afeto, com pagamento pelos serviços prestados pela prostituta. Entre as provas, havia reproduções de páginas do site de prostituição do qual a vítima fazia parte (com tabela de preços cobrados). A defesa argumentara ainda que a mulher tinha outros clientes. Na tribuna, durante o julgamento, o advogado do réu se referira à vítima como o exemplo da "mulher tsunami": "Começa fazendo onda e depois leva tudo do parceiro."

Já os advogados da garota de programa reuniram fotos, reproduções de e-mails e depoimentos para comprovar a relação afetiva entre o casal, apesar do fato da vítima não negar fazer programas com outras pessoas. De acordo com a acusação, os dois se aproximaram através de um site de relacionamentos e não de prostituição (do qual ela fazia parte também). 
O julgamento do recurso na Segunda Câmara Criminal teve o desembargador José Muiños Piñeiro Filho como relator. Ele ficou convencido que o relacionamento teve um lado afetivo. Fotos mostravam o réu com o filho da vítima durante um jogo de futebol, em almoços com a família dela (com a presença da mãe da prostituta) e outros momentos de lazer.

“Apesar de comprovadamente a vítima ser garota de programa, inclusive com site de propaganda e divulgação de preços, e ela não ter negado esta condição, mantive a condenação por entender que a questão não era de mera relação contratual entre cliente e serviços sexuais oferecidos pela vítima, como sustentava a defesa. Réu e vítima mantiveram relações por seis anos. Eles se conheceram em site de relacionamento e não de programa sexual. Passou a frequentar a casa dela e vice-versa. Havia fotos dele ao lado da vítima em momentos de descontração, como em barcos em Angra do Reis, em clubes e em almoços com a família dela. Situações que indicavam descontração e carinho e não apenas companhia profissional e paga" - afirma o desembargador.

O conjunto de provas, na avaliação de Piñeiro, mostrou que "ainda que ele pagasse algumas vezes pelos programas ou ajudasse financeiramente e mesmo sabendo que ela fazia programas com outros homens, havia relação de afeto e, com isso, a aplicação da Lei Maria da Penha". O desembargador destaca especialmente o artigo 5, inciso III: "para efeitos da lei, configura violência doméstica e familiar contra a mulher qualquer ação ou omissão baseada no gênero que lhe cause morte, lesão...; em qualquer relação íntima de afeto, na qual o agressor conviva ou tenha convivido com a ofendida, independentemente de coabitação.”

O tema, porém, provocou opiniões divergente entre os desembargadores da Segunda Câmara Criminal. Num determinado momento, por exemplo, foi citada uma troca de mensagens entre a vítima e uma amiga, na qual ela (a prostituta) reclamava que o empresário estava saindo com outra mulher (que ela chamava de "velha"). Uma desembargadora concluiu que isso demonstrava que a garota de programa estava apenas preocupada com a possível perda de sua "galinha dos ovos de ouro". A outra desembargadora, porém, entendeu como a reação de uma mulher "despeitada" com a presença de outra mulher no relacionamento. Em outras palavras: ciúme.

Ao final dos argumentos, dois desembargadores acompanharam o voto de Piñeiro. E dois divergiram no entendimento de que caberia a aplicação da Lei Maria da Penha. Mas, por três votos a dois, foi mantida a condenação com aplicação dessa lei. 
Na avaliação do desembargador a decisão inédita é um avanço: "Esse tema me trouxe a lembrança de uma discussão jurídica antiga e que, felizmente, com o tempo, foi superada. Saber se uma prostituta poderia ser vítima de estupro. Quando eu comecei a estudar Direito, nos anos 70, era dividida na época a opinião dos juristas a respeito desse tema" - acrescenta ele.

Há também um posicionamento de um juiz de Direito a respeito do tema. O juiz, Gerivaldo Lima, em entrevista dada a um programa de televisão em 2010, defende que a LMP pode ser estendida a casos de agressão a profissionais do sexo. Ele diz que não recebeu muito apoio, salvo das interessadas diretamente no assunto. Gerivaldo destaca algumas vantagens que garotas de programa teriam ao serem amparadas pela Lei, tais como: "essas mulheres não seriam mais humilhadas em delegacias de polícia e receberiam toda a proteção prevista na Lei Maria da Penha, além disso, seus agressores seriam punidos com os rigores da mesma Lei”. (LIMA, 2010).

Na mesma entrevista, Gerivaldo lembra de decisões do STF em casos não comuns de aplicação da LMP, como por exemplo, casais de namorados. Lembrou também de uma decisão do ministro Jorge Mussi, de que não é necessário que morem na mesma casa para existir uma relação de intimidade entre ambos, em caso de ocorrer violência doméstica. Portanto, o juiz não vê impedimentos em se aplicar a Lei, em ocasiões que caibam, à agressões contra garotas de programa. (LIMA, 2010).

Segundo um estudo publicado pela revista dedicada ao público masculino, Men and Masculinities, pelo menos um terço dos homens entrevistados, admitiu o desejo de um envolvimento além do sexo com uma garota de programa. De acordo com Christine Milrod, psicoterapeuta que realizou o estudo, muitos casos de envolvimentos de homens com garotas de programa acabam criando vínculos afetivos, não é uma coisa tão incomum. A prostituta acaba por se tornar uma parceira perfeita, na idealização de alguns homens, por combinar a excelência do sexo com o romantismo. (MILROD, 2016).

É evidente que há sim a existência de vínculos sentimentais entre profissionais do sexo e seus clientes, visto que, há relatos dos próprios homens não negando o desejo de ter esse tipo de vínculo e como prova jurídica, há a decisão inédita do Tribunal de Justiça do Rio que foi favorável a vítima por levar em conta todas as provas existentes de relacionamento afetivo, fora do ambiente de programa sexual, que existia entre o agressor e a vítima. 
Há ainda materiais publicados na dramaturgia e na literatura, baseados em fatos reais quem exaltam exatamente essa relação afetiva entre garota de programa e cliente. Como o filme "Uma Linda Mulher", lançado em 1990 e estrelado por Julia Roberts e Richard Gere, onde conta uma história de amor vivida por uma prostituta e um cliente, o filme é um clássico dos cinemas e encontra-se na categoria de romance. (UMA LINDA MULHER, 1990).

No Brasil há o livro “O Doce Veneno do Escorpião" lançado em 2005, que se trata de uma autobiografia de Raquel Pacheco, que posteriormente virou filme e série, contatando a história da mesma, uma profissional do sexo conhecida como "Bruna Surfistinha" que dentre centenas de clientes que tivera, um se declarava sempre apaixonado por ela e por diversas vezes a pediu para mudar de vida e ficar com ele. Raquel declara-se hoje não mais prostituta e casada com esse mesmo cliente. (O DOCE VENENO DO ESCORPIÃO, 2005).

Portanto, não é algo fantasioso nem mentiroso e sob essa circunstância fica o questionamento: Qual o impedimento em se aplicar a Lei Maria da Penha a agressões domésticas cometidas contra profissionais do sexo? Se o tipo da relação do criminoso com a ofendida se enquadrar nos casos citados acima, classificados como relação afetiva, não há razão lógica para uma negativa por parte do judiciário em se fazer cumprir a Lei e empregar a norma 11.340/06 nas circunstâncias adequadas.

Mesmo que o vínculo afetivo não seja necessariamente amoroso, mas pode ser de amizade, carinho, companheirismo, proximidade, enfim, há diversas formas de sentimentos, o que torna a relação algo mais que casual e sexual.

$\mathrm{O}$ artigo $2^{\circ}$ da Lei 11.340/2006, afirma que:

Toda mulher, independentemente de classe, raça, etnia, orientação sexual, renda, cultura, nível educacional, idade e religião, goza dos direitos fundamentais inerentes à pessoa humana, sendo-lhe asseguradas as oportunidades e facilidades para viver sem violência, preservar sua saúde física e mental e seu aperfeiçoamento moral, intelectual e social (BRASIL, 2006).

O artigo não faz distinção entre tipos de mulheres, é muito claro ao expor, "toda mulher", sendo assim é adequado e justo que garotas de programas ao sofrer violência doméstica devam e mereçam dispor da mesma lei que atende a outras mulheres na mesma circunstância, se assim precisar.

Contudo, o que levaria um homem a cometer tipos de violência contra uma mulher prostituta - mesmo existindo um relacionamento sentimental entre eles? 
Em entrevista dada a repórter Nayara Kobori, para o jornal digital "Repórter Unesp", a professora de história Fabiana Rodrigues afirma que a explicação para isto é construção histórica. A sociedade foi construída sob a égide de uma sociedade patriarcal, onde o homem é quem toma as decisões e comanda o lar, e a mulher obedece e se submete. Por sua vez, toda mulher que se encontrasse fora desse modelo, era tratada de forma diferenciada e minimizada, imagine então uma mulher que usava seu corpo para ganhar dinheiro através do sexo, que sempre foi um verdadeiro 'tabu' dentro dos lares, era então motivo de desonra e vergonha para as demais e razão suficiente para serem menosprezadas, usadas e desconsideradas pelo povo. (RODRIGUES, 2014).

Fabiana Rodrigues afirma que:

As práticas violentas contra as mulheres - concebidas como gênero de construção
social, ou seja, independente de condições biológicas - são frutos do reforço de
modelos, práticas sociais e instituições que estereotipam a figura da mulher. As
mulheres são, de certa forma, educadas para agradar ao outro - ao homem
principalmente. E esse tipo de educação vai fazendo com que as mulheres
renunciem à autonomia (RODRIGUES, 2014).

Por conseguinte, entende-se que, o homem construiu uma sensação de poder sobre a mulher de forma geral. Se o homem, sustentado pelas raízes de uma sociedade patriarcal e machista, acha que tem poder sobre qualquer mulher, quanto mais sobre uma prostituta que é objetificada sexualmente. Onde seria o dever delas apenas satisfazer o homem e submeter-se a ele em qualquer situação, caso contrário a isso, elas "merecem ser agredidas" para aprender lições.

E, quando existe algum tipo de sentimento da parte do agressor pela vítima, é raramente assumido, por motivo de vergonha em sua maioria. Nenhum homem quer ter sua imagem associada a uma prostituta, pelo menos não publicamente. Nesses casos, é provável que a sensação de domínio seja ainda maior, uma vez que envolve laços emocionais, e quando mexe com o emocional torna-se tudo mais delicado e de certa forma, perigoso. Portanto, o desejo de posse é grande, certamente acometido pelo sentimento que há, e essa possessividade pode levar a um índice de violências sofridas quando houver desagrado por parte da vítima para com o agressor.

Sendo assim, não há dúvidas da existência da tipificação penal de violência doméstica com base no gênero contra profissionais do sexo, de forma igual, não deveria ter dúvidas também quanto a aplicação da Lei Maria da Penha nos delitos do tipo, nem 
qualquer resistência por parte do judiciário ou da população, vez que, a Lei é garantida para todos e há todos deve recair.

\section{CONSIDERAÇÕES}

Os casos de violência doméstica e familiar podem ser verificados, mesmo que, porventura, os agressores estejam cientes de que podem sofrer sanções legais. Essas sanções, por si só, não são capazes de intimidá-los a ponto de diminuir as intenções de agressão das companheiras. Não obstante a isso, a criação da Lei Maria da Penha representou um grande avanço para o sistema judiciário brasileiro e aumentou consideravelmente a quantidade de processos por violência doméstica.

Ressalta-se as inovações e melhorias trazidas pela Lei que modificou o cenário penal no que concerne à violência contra a mulher, vez que, criou mecanismos específicos para atuar nesse campo, e as punições passaram a ser mais eficientes, já que anterior a criação da LMP não era satisfatória. A Lei Federal n. 11.340/2006 mostrou-se mais que sensata, atendendo a situação contemporânea de intolerância à violência de gênero. Isso dá respaldo para a restrição dessa conduta.

Observou-se que a Lei 11.340/06 atinge uma proteção mais abrangente as mulheres no decorrer dos tempos e dos acontecimentos, devido a decisões incomuns impetradas pelo judiciário, tais como, aplicação da referida Lei em casos de agressões contra mulheres membros da família consanguínea, contra namoradas ou ex-namoradas, relacionamentos abertos mas que haja o vínculo afetivo e a célebre e inédita decisão do TJ do Rio que aplicou em favor de uma profissional do sexo.

A Lei Maria da Penha, resultado de incessantes esforços de movimentos feministas, bem como, a percepção da necessidade da existência de um método que fizesse frente a forma desigual e agressiva com que sempre fora tratada as mulheres, foi um mecanismo trazido pelo Direito brasileiro que resultou em diferenças aos índices de violência contra a mulher, visto que, adotou meios punitivos mais rigorosos sobre os quais existia anteriormente, e graças a evolução dos tempos e da sociedade, é dada cada vez mais voz a essa norma, como incentivo a mulher buscar sua proteção e não mais aceitar ser discriminada e violentada por que homens acham que podem se sobrepor a elas.

Faz-se mister salientar que, diante de tudo que se fora estudado, percebeu-se que a figura feminina dos tempos atuais não é a mesma de anos atrás, a cada tempo, o 
empoderamento feminino torna-se mais presente e apesar da questão da violência de gênero ainda ser bastante presente, mulheres estão mais determinadas a lutarem por seu direito de não sofrer nenhum tipo de violência, com respaldo, principalmente, na legalidade da Lei $11.340 / 06$.

Através dos estudos feitos para realização desse trabalho, verificou-se também, acerca da prostituição, que esta, é mais uma das formas de dominação sob o gênero do masculino para o feminino, pois a profissional do sexo, encontra-se na maioria das vezes em situação de menosprezo e objetificação sexual, onde são usadas, em grande, parte para a satisfação do cliente, fora isso, são censuradas, marginalizadas, discriminadas, entre outras práticas negativas impostas pela sociedade a estas.

É relevante lembrar da necessidade de práticas não discriminatórias como forma de reduzir a violência de gênero, como nos casos de agressões a profissionais do sexo, que por vezes são preteridas como se não fosse um problema grave, como quando ocorre com outras mulheres. É necessário se dar a mesma atenção a estes casos, ter o mesmo respeito e ajudar da mesma forma que se faria em casos de violência a mulheres que não são prostitutas.

Destaca-se que ao longo do trabalho, foi trazida a possibilidade do emprego da LMP a violência doméstica cometida á garotas de programa, pois, se o tipo de violência sofrida se enquadrar no tipo penal proposto pela Lei, não há nenhum empecilho para isso, o fato de haver divergências doutrinárias e da sociedade, não muda o que está escrito na letra da Lei, dessa forma a sua aplicabilidade torna-se legal para proteger cada vez mais um maior número de mulheres que necessite, haja visto que, essa é a intenção de toda norma, proteger os indivíduos de uma sociedade, garantindo a eles, entre outros, direitos.

A adoção do procedimento mais austero para combater a violência baseada no gênero, assim como, uma maior abrangência da Lei, estendendo a qualquer tipo de violência contra a mulher, não se restringindo apenas a violência doméstica e familiar, tal qual, a inclusão de qualquer pessoa como agressor, não somente homens, ainda deveria ser melhor analisada, para combater o problema, à proporção em que a Justiça se adapta aos anseios do texto legal.

Pelo fato dessas mulheres sofrerem constantes agressões, seria adequado existir um capítulo específico nesta Lei, de proteção a elas. Uma vez que o objetivo da Lei é a proteção e assistência a mulher que sofre violência doméstica, portanto, deveria ter uma atenção especial ao grupo de mulheres que assim necessitasse, como no caso das garotas de programa. 
Mas enquanto isso não é possível, o correto é ser subsidiada pelo que há na Lei como garantia de igualdade de direitos e cidadania. Ao avaliar os precedentes expostos acima, conclui-se que a violência atinge de forma mais vasta as mulheres, por isso há a categoria da violência baseada no gênero, que de acordo com o exposto, se dá principalmente pela forma menosprezada com que a mulher fora tratada ao longo dos anos e que influencia na sociedade até nos dias atuais.

Então não há o que se questionar se profissionais do sexo devam recorrer ou não a uma delegacia de atendimento especializado a mulher para tomar as devidas providências, exercendo seus direitos como mulher.

\section{REFERÊNCIAS}

SILVA, Kenia Costa. Mecanismos de proteção frente à violência contra as mulheres com enfoque no plano interno. Disponível em: <https://jus.com.br/artigos/43428/mecanismos-deprotecao-frente-a-violencia-contra-as-mulheres-com-enfoque-no-plano-interno>. Acesso em: 22 dez. 2019.

KHOURI, José Naaman. Considerações Sobre a Violência de Gênero e Violência Doméstica Contra a Mulher. Disponível em: <https://dpmt.jusbrasil.com.br/noticias/3021506/artigo-consideracoes-sobre-a-violencia-de-genero-eviolencia-domestica-contra-a-mulher>. Acesso em: 02 jan. 2020.

BIANCHINNI, Alice. O que é "violência baseada no gênero"? Art. $5^{\circ}$ da Lei Maria da Penha. Disponível em: <https://professoraalice.jusbrasil.com.br/artigos/312151601/o-que-eviolencia-baseada-no-genero $>$. Acesso em: 02 jan. 2020.

TODAMATERIA. Feminismo. Disponível em: <https://www.todamateria.com.br/feminismo/>. Acesso em 03 jan. 2020.

SUPERIOR TRIBUNAL DE JUSTIÇA. Violência doméstica: cinco anos de punição mais rígida para agressores. Disponível em: <https://stj.jusbrasil.com.br/noticias/2840203/violencia-domestica-cinco-anos-de-punicaomais-rigida-para-agressores >. Acesso em 03 jan. 2020.

CONSELHO NACIONAL DE JUSTIÇA. Formas de violência contra a mulher. Disponível em: <http://www.cnj.jus.br/programas-e-acoes/lei-maria-da-penha/formas-de-violencia>. Acesso em: 20 jan. 2020.

KRUG, E. G. et al. (Org.). Relatório mundial sobre violência e saúde. Geneva: Organização Mundial da Saúde, 2002.

COMPROMISSO E ATITUDE. Dados e estatísticas sobre violência contra as mulheres. Disponível em: <http://www.compromissoeatitude.org.br/dados-e-estatisticas-sobreviolencia-contra-as-mulheres/>. Acesso em: 21 jan. 2020. 
ALMEIDA, Maria da Graça Blaya. A Violência na sociedade Contemporânea. Porto Alegre: Edipucrs, 2010. Disponível em: <http://ebooks.pucrs.br/edipucrs/violencia.pdf>. Acesso em 17 jan. 2020.

CAMPOS, Amanda. Todos os anos, três milhões de meninas sofrem mutilação genital no mundo. Disponível em: <http://ultimosegundo.ig.com.br/mundo/2015-04-22/todos-os-anostres-milhoes-de-meninas-sofrem-mutilacao-genital-no-mundo.html>. Acesso em: 10 jan. 2020.

BOTELHO, José Francisco. Bruxas por trás da caça. Disponível em: <https://super.abril.com.br/historia/bruxas-por-tras-da-caca/>. Acesso em: 22 jan. 2020.

IHERING, Rudolf Von. A Luta Pelo Direito. Rio de Janeiro. 1909. Disponível em: $<$ https://portalconservador.com/livros/Rudolf-Ihering-A-Luta-pelo-Direito.pdf $>$. Acesso em: 22 jan. 2020.

ALVES, Magno. Os tipos mais comuns de violência praticados contra as mulheres são física, sexual e psicológica. <https://toinhoffilho.blogspot.com.br/2017/03/os-tipos-mais-comuns-de-violencia.html>. Acesso em 01 fev. 2020.

ALBERTO, Carlos. Curso de Ética Jurídica. Ética geral e profissional. 7. a ed.; São Paulo: Saraiva, 2010; p. 458.

LACERDA, Rosane Freire; JUNQUEIRA, Mariane Oliveira. Ética Profissional Jurídica Regulamentação dos Profissionais do sexo. Um debate. Disponível em: <http://direitopublicoediversidade.blogspot.com.br/2010/10/etica-profissional-juridica.html.>. Acesso em: 01 fev. 2020.

NUCCI, Guilherme de Souza. Prostituição, Lenocínio e Tráfico de Pessoas: Aspectos Constitucionais e Penais. $2^{\mathrm{a}}$ ed: Gen. 2015. Disponível em: $<$ http://www.guilhermenucci.com.br/dicas/conceito-de-prostituicao>. Acesso em: 03 fev. 2020.

https://www.direitonet.com.br/artigos/exibir/6567/Sujeitos-do-crime-de-genero-na-Lei11340-06-Lei-Maria-da-Penha

https://www.conjur.com.br/2015-nov-08/quando-sujeito-ativo-lei-maria-penha-sexofeminino- CAPEZ, Fernando. Curso de Direito Penal: Parte Geral. 10. Ed. São Paulo: Saraiva, 2006

- MIRABETE, Julio Fabbrini. Sujeito Ativo do crime. Disponível em:. Acesso em: 26 out. 2020

Disponível em: https://mateuscminuzzi.jusbrasil.com.br/artigos/118288535/aplicacao-da-leimaria-da-penha-as-vitimas-do-sexo-masculino-e-as-relacoes-homoafetivas

ROXIN, Claus. A proteção de bens jurídicos como função do direito penal. Org. e Trad. André Luís Callegari e Nereu José Giacomolli. Porto Alegre: Livraria do Advogado, 2006 
PRADO, Luiz Regis. Bem Jurídico-Penal e Constituição. Editora Revista dos Tribunais, $3^{\text {a }}$ edição, 2003

WALTHER, L. Orientação profissional e as carreiras liberais. Edições Melhoramentos. São Paulo. 1962 